\title{
Synthesis and In vitro Antimicrobial Activity of Novel 2-(4-(Substituted-carboxamido)benzyl / phenyl)benzothiazoles
}

\author{
Serap Yilmaz, ${ }^{\mathrm{a}}$ Ismail Yalcin, ${ }^{\mathrm{a}}$ Fatma Kaynak-Onurdag, ${ }^{\mathrm{b}}$ Selda Ozgen, ${ }^{\mathrm{b}}$ \\ Ilkay Yildiz, ${ }^{\text {a,* }}$ and Esin Aki ${ }^{a}$ \\ ankara University, Faculty of Pharmacy, Department of Pharmaceutical Chemistry, 06100, Tandoğan, Ankara, Turkey \\ ${ }^{\mathrm{b}}$ Gazi University, Faculty of Pharmacy, Department of Pharmaceutical Microbiology, 06330, Etiler, Ankara, Turkey
}

\begin{abstract}
A new series of 2-[4-(4-substitutedbenzamido / phenylacetamido / phenylpropionamido) benzyl / phenyl]benzothiazole derivatives $(\mathbf{6 a}-\mathbf{6 w})$ were synthesized and evaluated for antibacterial and antifungal activities against Staphylococcus aureus, Bacillus subtilis, Klebsiella pneumoniae, Pseudomonas aeruginosa, Escherichia coli with their drug-resistant isolates and a yeast Candida albicans. Microbiological results indicated that the compounds possessed a broad spectrum of activity against the tested microorganisms at MIC values between 200 and $6.25 \mu \mathrm{g} / \mathrm{ml}$. Compounds $6 \mathbf{e}$ and $\mathbf{6 j}$ exhibited the greatest activity with MIC values of $6.25 \mu \mathrm{g} / \mathrm{ml}$ against Pseudomonas aeruginosa, and Staphylococcus aureus isolate, respectively.(doi: 10.5562/cca2064)
\end{abstract}

Keywords: benzothiazole, antibacterial activity, antifungal activity, multi-drug resistance

\section{INTRODUCTION}

Bacterial resistance to antibacterial agents or antibiotics is of grave concern in the medical community, as many species of bacteria have evolved resistance to certain antibiotics and synthetic agents. Therefore, there could be a rapidly growing global crisis in the clinical management of life-threatening infectious diseases caused by multidrug-resistant strains of the Gram-positive pathogens like Streptococcus, Enterococcus, and Staphylococcus, and Gram-negative pathogens like Escherichia, Salmonella, and certain Pseudomonas strains. Especially the emergence of multidrug-resistant strains of Gram-positive bacterial pathogens such as methicillin-resistant Staphylococcus aureus and Staphylococcus epidermis and vancomycin-resistant Enterococcus is an alarming problem of ever increasing significance. ${ }^{1-4}$ To meet this crisis successfully, many researchers across the globe are working to unearth new compounds which can selectively attack novel targets in microorganisms. Hence, the development of novel, potent, and unique antibacterial agents is the preeminent way to overcome bacterial resistance and develop effective therapies. ${ }^{5}$

The compounds possess benzothiazole nucleus in their structure are involved in research aimed at evaluating new chemotherapeutically active agents: such as antimicrobial $^{6-9}$ a topical carbonic anhydrase inhibitor, ${ }^{10}$ a cyclooxygenase inhibitor, ${ }^{11}$ antitubercular, ${ }^{12,13}$ antinematode, ${ }^{14}$ a dual inhibitor of thromboxane $\mathrm{A}_{2}$ synthetase and 5-lipoxygenase ${ }^{15}$, a selective and reversible inhibitor of monoamine oxidase type A (MAOA), ${ }^{16}$ antiallergic ${ }^{17}$ multi-drug resistance cancer cell activities with inhibiting activity on eukaryotic topoisomerase II enzyme in cell-free system ${ }^{18-20}$ and antitumor agents. ${ }^{21-23}$

Currently, a new series of benzothiazoles have been synthesized as antitumor agents and showed potent inhibitory activity against human breast cancer cell lines in vitro and in vivo. ${ }^{21}$ Among them, lysyl-amide of 2-(4amino-3-methylphenyl)-5-fluorobenzothiazole (Formula 1) had been selected for phase 1 clinical evaluation. ${ }^{22}$

In the last years, we reported the synthesis of several 2-substitutedbenzothiazole derivatives as the anti-

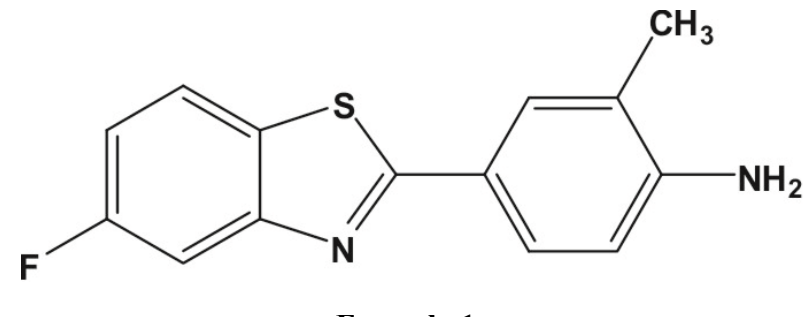

Formula 1.

\footnotetext{
* Author to whom correspondence should be addressed. (E-mail: iyildiz@pharmacy.ankara.edu.tr)
} 


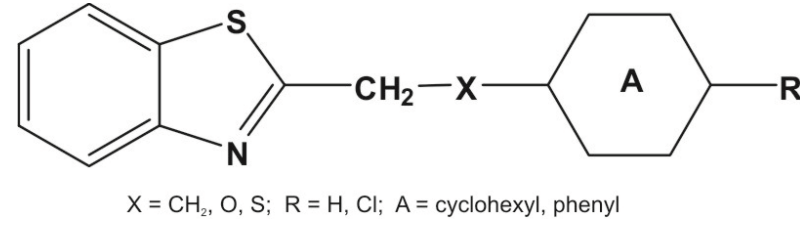

Formula 2.

microbial agents ${ }^{7,8}$ as seen in Formula 2. According to these studies the compounds were found to have inhibitory effect with MIC value of $3.12-50 \mu \mathrm{g} / \mathrm{ml}$ against some of Gram-positive, Gram-negative bacteria and Candida albicans as yeast. Among the tested compounds, 2-(phenoxymethyl)benzothiazole was found the most active derivative at a MIC value of $3.12 \mu \mathrm{g} / \mathrm{ml}$ against the tested $S$. aureus. ${ }^{8}$ Moreover, the same compound was found very potent as an eukaryotic topoisomerase II inhibitor exhibiting a better inhibitor activity than reference drug ${ }^{18-20}$ etoposide.

Currently, we reported the synthesis and the antimicrobial activity of 2-[4-(4-substituted-benzamido/phenylacetamido)phenyl]benzothiazole derivatives $(7 \mathbf{a}-7 \mathbf{k}) .{ }^{24}$ In continuation to our ongoing research work on new 2-(4-carboxamido-benzyl / phenyl)benzothiazole derivatives, herein, we described the synthesis and in vitro antimicrobial activity of novel 2-[4-(4-substitutedbenzamido / phenylacetamido / 3-phenylpropionamido) benzyl / phenyl]benzothiazoles (6a-6w) (Formula 3) against different Gram positive (Staphylococcus aureus, Bacillus subtilis) and Gram-negative (Klebsiella pneumoniae, Pseudomonas aeruginosa, Escherichia coli) bacteria with their drug-resistant isolates as well as the yeast $C$. albicans in comparison with several control drugs, including structure-activity relationship (SAR) studies.

\section{EXPERIMENTAL}

\section{Chemistry}

The chemicals were purchased from the commercial venders and were used without purification. The reactions were monitored and the purity of the products was

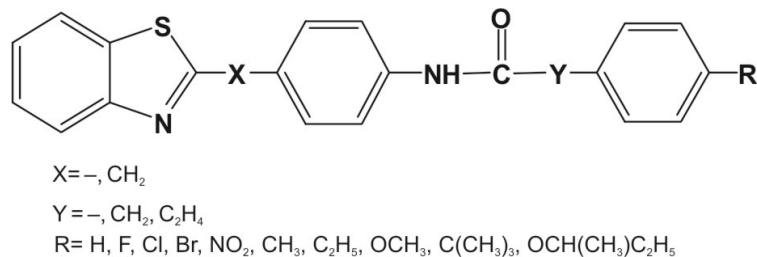

Formula 3.

checked by thin layer chromatography (TLC). Silicagel HF254 chromatoplates $(0.3 \mathrm{~mm})$ were used for TLC and the solvent systems were $n$-hexan:ethyl acetate $(2: 1)$ for 2-(4-aminobenzyl/phenyl)benzothiazole (3) and chloroform:methanol (20:1) for compounds $\mathbf{6 a}-\mathbf{6 w}$. Melting points were taken on a Buchi SMP 20 capillary apparatus and are uncorrected. IR spectra were recorded by FT/IR-420 in KBr discs. ${ }^{1} \mathrm{H}$ NMR spectra were obtained with a Varian Mercury 400 High Performance Digital FT-NMR-400 $\mathrm{MHz}$ spectrometer in $\mathrm{d}_{6}$-chloroform, tetramethylsilane (TMS) was used as an internal standard. Elemental analyses were carried out with CHNS932 (LECO) apparatus. The results $(\mathrm{C}, \mathrm{H}, \mathrm{N})$ were within $\pm 0.4 \%$ of the calculated values. Mass analysis was obtained by Waters 2695 Alliance ZQ Micromass LCMS working with ESI apparatus.

General Procedure for the Synthesis of 2-(4aminobenzyl/phenyl)benzothiazole (3)

2-(4-aminobenzyl/phenyl)benzothiazole (3) were prepared by heating $1 \mathrm{mmol} o$-aminothiophenol (1) with 1 mmol $p$-aminobenzoic acid / $p$-aminophenylacetic acid (2) in $2.4 \mathrm{~g}$ polyphosphoric acid and stirring for $4 \mathrm{~h}$ (Scheme 1). After then the residue was poured into icewater mixture and neutralized with excess of $10 \% \mathrm{NaOH}$ solution. The precipitate was boiled with activated charcoal in ethanol and then, filtered and recrystallized in

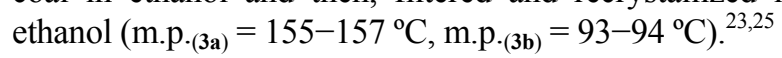

General procedure for the synthesis of compounds (6a-6w)

The result products, 2-[4-(4-substitutedbenzamido/phenylacetamido/3-phenyl propionamido)benzyl/phenyl]benzothiazole derivatives $(\mathbf{6 a}-\mathbf{6} \mathbf{w})$ were synthesized by<smiles>Nc1ccccc1S</smiles>
1<smiles>[X]C(=O)O</smiles>
2

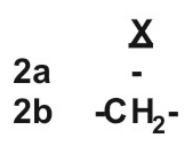<smiles>[PbH]</smiles><smiles>[X]c1ccc(N)cc1</smiles>

3

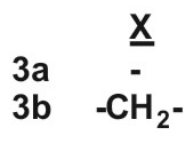

Scheme 1. Synthesis of 2-(4-aminobenzyl / phenyl)benzothiazoles. 


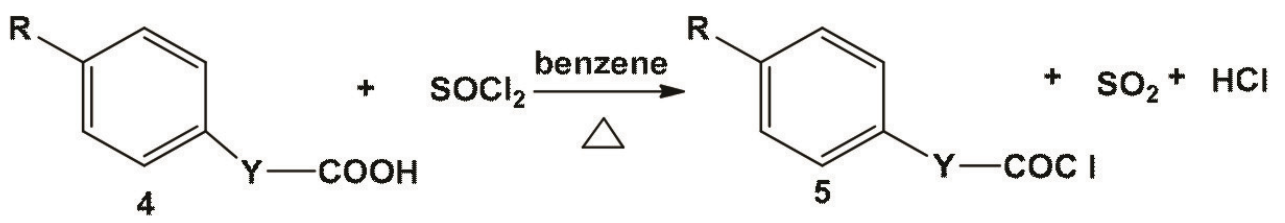

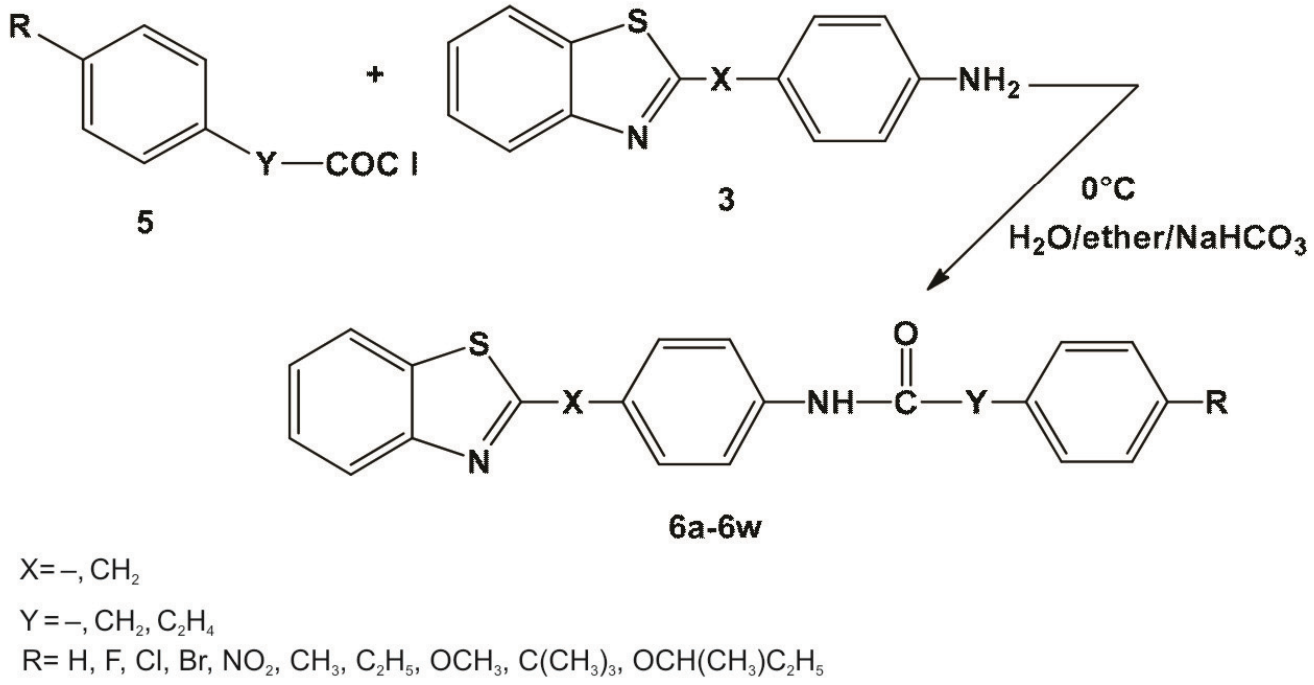

Scheme 2. General synthetic pathway of compounds $6 \mathbf{a}-\mathbf{6 w}$.

heating thionyl chloride $(0.3 \mathrm{ml})$ and appropriate carboxylic acid (4) $(1 \mathrm{mmol})$ in benzene $(0.5 \mathrm{ml})$ at $80^{\circ} \mathrm{C}$ for $3 \mathrm{~h}$, and then excess thionyl chloride was removed in vacuo (Scheme 2). The residue was dissolved in ether (1 $\mathrm{ml})$ and solution added during $1 \mathrm{~h}$ to a stired, ice-cold mixture of 2-(4-aminobenzyl/phenyl)benzothiazole (1 $\mathrm{mmol})$, sodium bicarbonate $(2 \mathrm{mmol})$, diethylether $(1$ $\mathrm{ml})$ and water $(1 \mathrm{ml}){ }^{26}$ The mixture was kept stirred overnight at room temperature and then filtered. After the precipitate was washed with water, $2 \mathrm{~N} \mathrm{HCl}$ and water. Ethanol was used for recrystallization and crystals are dried in vacuo.

\section{2-[4-(benzamido)phenyl]benzothiazole $(\mathbf{6} \boldsymbol{a})^{23}$}

Yield: $52 \%$; m.p. $=222-224{ }^{\circ} \mathrm{C}$; IR $v / \mathrm{cm}^{-1}: 3366,2924$, 1658 (Amid I), 1599, 1531(Amid II), 1510, 1481, 1435 (Amid III), 967-626, 730-626; ${ }^{1} \mathrm{H}$ NMR (400 MHz, $\mathrm{CDCl}_{3}$ ) $\delta / \mathrm{ppm}: 7.389$ (t, $\left.J=7.6 \mathrm{~Hz}, J=7.6 \mathrm{~Hz}, 1 \mathrm{H}\right)$, $7.480-7.547$ (m, 3H), 7.587 (d, $J=7.2 \mathrm{~Hz}, 1 \mathrm{H}), 7.823$ (d, J=8 Hz, 2H), 7.899-7.918 (m, 3H), $7.960(\mathrm{~s}, 1 \mathrm{H})$, $8.064(\mathrm{~d}, J=7.6 \mathrm{~Hz}, 1 \mathrm{H}), 8.125(\mathrm{~d}, J=8.8 \mathrm{~Hz}, 2 \mathrm{H})$; ESI $(+) m / \mathrm{e}: 331.33\left(\mathrm{M}^{+}+\mathrm{H}\right)(\% 100)$; anal. found: $\mathrm{C}$ 72.94, H 4.03, N 8.90, S 9.80; calcd. for $\mathrm{C}_{20} \mathrm{H}_{14} \mathrm{~N}_{2} \mathrm{OS}$. $0.01 \mathrm{HCl}: \mathrm{C} 72.94, \mathrm{H} 4.24, \mathrm{~N} 8.48$, S 9.68.

2-[4-(4-sec-butoxybenzamido)phenyl]benzothiazole (6b) Yield: $54 \%$ : m.p. $=211-213{ }^{\circ} \mathrm{C}$; IR $v / \mathrm{cm}^{-1}: 3318,2968$, 2928, 1649 (Amid I), 1604, 1518 (Amid II), 1502, 1480, 1435 (Amid III), 1251, 1032, 966-628, 727-628; ${ }^{1} \mathrm{H}$
NMR (400 MHz, $\mathrm{CDCl}_{3}$ ) $\delta /$ ppm: $0.996(\mathrm{t}, J=7,6 \mathrm{~Hz}, J$ $=7.6 \mathrm{~Hz}, 3 \mathrm{H}), 1.336(\mathrm{~d}, J=6.4 \mathrm{~Hz}, 3 \mathrm{H}), 1.579-1.817$ $(\mathrm{m}, 2 \mathrm{H}), 4.382-4.428(\mathrm{~m}, 1 \mathrm{H}), 6.962(\mathrm{~d}, J=8,8 \mathrm{~Hz}$, 2H), $7.380(\mathrm{t}, J=7.2 \mathrm{~Hz}, J=7.2 \mathrm{~Hz}, 1 \mathrm{H}), 7.490(\mathrm{t}, J=$ $8 \mathrm{~Hz}, J=8.4 \mathrm{~Hz}, 1 \mathrm{H}), 7.799$ (d, $J=9.2 \mathrm{~Hz}, 2 \mathrm{H}), 7.848$ $(\mathrm{d}, J=8.8 \mathrm{~Hz}, 2 \mathrm{H}), 7.900(\mathrm{~d}, J=8 \mathrm{~Hz}, 1 \mathrm{H}), 7.927$ (s, $1 \mathrm{H}), 8.054(\mathrm{~d}, J=8.4 \mathrm{~Hz}, 1 \mathrm{H}), 8.099$ (d, $J=8.4 \mathrm{~Hz}$, $2 \mathrm{H})$; ESI $(+) m / \mathrm{e}: 403.40\left(\mathrm{M}^{+}+\mathrm{H}\right)(\% 100)$; anal. found: $\mathrm{C} 71.31, \mathrm{H}$ 5.50, $\mathrm{N} 7.08, \mathrm{~S}$ 8.13; calcd. for $\mathrm{C}_{24} \mathrm{H}_{22} \mathrm{~N}_{2} \mathrm{O}_{2} \mathrm{~S}$ : C 71.62, H 5.51, N 6.96, S 7.97.

2-[4-(phenylacetamido)phenyl]benzothiazole (6c)

Yield: $15 \%$; m.p. $=203-205{ }^{\circ} \mathrm{C}$; IR $v / \mathrm{cm}^{-1}: 3305,3054$, 1660 (Amid I), 1600, 1545 (Amid II), 1504, 1482, 1434 (Amid III), 979-621, 728-621; ${ }^{1} \mathrm{H}$ NMR (400 MHz, $\mathrm{CDCl}_{3}$ ) $\delta / \mathrm{ppm}: 3.778(\mathrm{~s}, 2 \mathrm{H}), 7.323-7.496(\mathrm{~m}, 8 \mathrm{H})$, $7.573(\mathrm{~d}, J=8.4 \mathrm{~Hz}, 2 \mathrm{H}), 7.880(\mathrm{~d}, J=8 \mathrm{~Hz}, 1 \mathrm{H})$, 7.994-8.042 (m, 3H); ESI $\quad(+) \quad m / e: 345.36$ $\left(\mathrm{M}^{+}+\mathrm{H}\right)(\% 100)$; anal. found: C 72.37, H 5.02, N 8.47, S 9.32; calcd. for $\mathrm{C}_{21} \mathrm{H}_{16} \mathrm{~N}_{2} \mathrm{OS} \cdot 0.15 \mathrm{H}_{2} \mathrm{O}: \mathrm{C} 72.65, \mathrm{H}$ 4.73, N 8.07, S 9.23.

2-[4-(4-nitrophenylacetamido)phenyl]benzothiazole(6d) Yield: $27 \%$; m.p. $=250-252{ }^{\circ} \mathrm{C}$; IR v/cm $\mathrm{cm}^{-1}$ : 3296, 1665 (Amid I), 1612-1591, 1539 (Amid II), 1521, 1481, 1434 (Amid III), 1350, 966-618, 726-618; ${ }^{1} \mathrm{H} \quad \mathrm{NMR}$ (400MHz, DMSO-d $\left.{ }_{6}\right) \delta /$ ppm: $3.928(\mathrm{~s}, 2 \mathrm{H}), 7.442(\mathrm{t}$, $J=6.8 \mathrm{~Hz}, J=8 \mathrm{~Hz}, 1 \mathrm{H}), 7.535$ (t, $J=7.2 \mathrm{~Hz}, J=8$ $\mathrm{Hz}, 1 \mathrm{H}), 7.651$ (d, $J=8.4 \mathrm{~Hz}, 2 \mathrm{H}), 7.828$ (d, $J=8.8$ 
$\mathrm{Hz}, 2 \mathrm{H}), 8.029$ (d, $J=8 \mathrm{~Hz}, 1 \mathrm{H}), 8.067(\mathrm{~d}, J=8.4 \mathrm{~Hz}$, $2 \mathrm{H}), 8.128$ (d, $J=8 \mathrm{~Hz}, 1 \mathrm{H}), 8.228$ (d, $J=8.4 \mathrm{~Hz}, 2 \mathrm{H})$, $10.472(\mathrm{~s}, 1 \mathrm{H})$; ESI (+) m/e: $390.35\left(\mathrm{M}^{+}+\mathrm{H}\right)(\% 100)$; anal. found: $\mathrm{C} 58.54, \mathrm{H} \mathrm{3.70,} \mathrm{N} \mathrm{9.85,} \mathrm{S} \mathrm{7.64;} \mathrm{calcd.} \mathrm{for}$ $\mathrm{C}_{21} \mathrm{H}_{15} \mathrm{~N}_{3} \mathrm{O}_{3} \mathrm{~S} \cdot 1.2 \mathrm{HCl}: \mathrm{C} 58.22, \mathrm{H} 3.76, \mathrm{~N} 9.70, \mathrm{~S}$ 7.40 .

2-[4-(3-phenylpropanamido)phenyl]benzothiazole (6e) Yield: $74 \%$; m.p. $=215-217^{\circ} \mathrm{C}$; IR $v / \mathrm{cm}^{-1}$ : 3314, 3027, 1658 (Amid I), 1598, 1533 (Amid II), 1506, 1480, 1434 (Amid III), 965-631, 728-620; ${ }^{1} \mathrm{H}$ NMR (400 MHz, $\mathrm{CDCl}_{3}$ ) $\delta / \mathrm{ppm}: 2.705$ (t, $J=7.6 \mathrm{~Hz}, J=7.6 \mathrm{~Hz}, 2 \mathrm{H}$ ), 3.078 (t, $J=8 \mathrm{~Hz}, J=7.2 \mathrm{~Hz}, 2 \mathrm{H}), 7.208-7.339$ (m, $5 \mathrm{H}), 7.375$ (t, $J=7.6 \mathrm{~Hz}, J=7.6 \mathrm{~Hz}, 1 \mathrm{H}), 7.483$ (t, $J=$ $8 \mathrm{~Hz}, J=7.2 \mathrm{~Hz}, 1 \mathrm{H}), 7.584(\mathrm{~d}, J=8.4 \mathrm{~Hz}, 2 \mathrm{H}), 7.890$ $(\mathrm{d}, J=7.6 \mathrm{~Hz}, 1 \mathrm{H}), 8.020-8.050(\mathrm{~m}, 3 \mathrm{H})$; ESI $(+) m / \mathrm{e}$ : $357.36\left(\mathrm{M}^{+}+\mathrm{H}\right)(\% 100)$; anal. found: $\mathrm{C} 72.77, \mathrm{H} 4.56, \mathrm{~N}$ 7.86, S 9.08; calcd. for $\mathrm{C}_{22} \mathrm{H}_{18} \mathrm{~N}_{2} \mathrm{OS} \cdot 0.18 \mathrm{HCl}$ : C 72.43, H 4.98, N 7.68, S 8.77.

\section{2-[4-(3-(4-metoxyphenyl)propanamido)phenyl]benzo-} thiazole (6f)

Yield: $59 \%$; m.p. $=223-225{ }^{\circ} \mathrm{C}$. IR $v / \mathrm{cm}^{-1}: 3281,3031$, 2990, 2933, 2831, 1651 (Amid I), 1609-1584, 1532 (Amid II), 1511, 1480, 1434 (Amid III), 1245, 1031, 967-621, 730-621; ${ }^{1} \mathrm{H}$ NMR (400 MHz, $\mathrm{CDCl}_{3}$ ) $\delta / \mathrm{ppm:}$ $2.674(\mathrm{t}, J=7.6 \mathrm{~Hz}, J=7.2 \mathrm{~Hz}, 2 \mathrm{H}), 3.023(\mathrm{t}, J=7.2$ $\mathrm{Hz}, J=7.6 \mathrm{~Hz}, 2 \mathrm{H}), 3.794$ (s, 3H), 6.858 (d, $J=8.4 \mathrm{~Hz}$, 2H), $7.128(\mathrm{~s}, 1 \mathrm{H}), 7.173(\mathrm{~d}, J=8.8 \mathrm{~Hz}, 2 \mathrm{H}), 7.374(\mathrm{t}, J$ $=7.2 \mathrm{~Hz}, J=8 \mathrm{~Hz}, 1 \mathrm{H}), 7.484(\mathrm{t}, J=8 \mathrm{~Hz}, J=7.6 \mathrm{~Hz}$, 1H), 7.587 (d, $J=8.4 \mathrm{~Hz}, 2 \mathrm{H}), 7.893$ (d, $J=7.6 \mathrm{~Hz}$, $1 \mathrm{H}), \quad 8.025-8.053(\mathrm{~m}, 3 \mathrm{H})$; ESI $(+) \mathrm{m} / \mathrm{e}: 389.40$ $\left(\mathrm{M}^{+}+\mathrm{H}\right)(\% 100)$; anal. found: $\mathrm{C} 68.67, \mathrm{H} 4.78, \mathrm{~N} 7.08, \mathrm{~S}$ 8.11; calcd. for $\mathrm{C}_{23} \mathrm{H}_{20} \mathrm{~N}_{2} \mathrm{O}_{2} \mathrm{~S} \cdot 0.4 \mathrm{HCl}$ : C $68.58, \mathrm{H}$ 5.06, N 6.95, S 7.95.

\section{2-[4-(benzamido)benzyl]benzothiazole (6g)}

Yield: $69 \%$; m.p. $=197-199{ }^{\circ} \mathrm{C}$; IR $v / \mathrm{cm}^{-1}: 3307,3113$, 3054, 2911, 1647(Amid I), 1601-1577, 1532 (Amid II), 1507, 1493, 1438 (Amid III), 974-605, 733-605. ${ }^{1} \mathrm{H}$ NMR (400 MHz, $\left.\mathrm{CDCl}_{3}\right) \delta / \mathrm{ppm}: 4.425$ (s, 2H), 7.3237.379 (m, 3H), 7.483-7.497 (m, 3H), $7.548(\mathrm{t}, J=7.2$ $\mathrm{Hz}, J=7.6 \mathrm{~Hz}, 1 \mathrm{H}), 7.641$ (d, $J=8 \mathrm{~Hz}, 2 \mathrm{H}), 7.801(\mathrm{~d}$, $J=8 \mathrm{~Hz}, 1 \mathrm{H}), 7.848-7.889(\mathrm{~m}, 3 \mathrm{H}), 7.995$ (d, $J=8.4$ $\mathrm{Hz}, 1 \mathrm{H})$. ESI $(+) m / \mathrm{e}: 345.32\left(\mathrm{M}^{+}+\mathrm{H}\right)(\% 100)$; anal. found: $\mathrm{C}$ 73.69, $\mathrm{H}$ 4.32, $\mathrm{N}$ 8.53, S 9.46; calcd. for $\mathrm{C}_{21} \mathrm{H}_{16} \mathrm{~N}_{2} \mathrm{OS}$ : C 73.23, H 4.68, N 8.13, S 9.31.

\section{2-[4-(4-fluorobenzamido)benzyl]benzothiazole (6h)}

Yield: $50 \%$; m.p. $=205-207{ }^{\circ} \mathrm{C}$; IR $v / \mathrm{cm}^{-1}$ : 3289, 1650 (Amid I), 1603, 1537 (Amid II), 1509, 1455, 1426 (Amid III), 1229, 942-618, 733-618; ${ }^{1} \mathrm{H}$ NMR (400 $\left.\mathrm{MHz}, \mathrm{CDCl}_{3}\right) \delta /$ ppm: 4.431 (s, 2H), 7.160 (t, $J=8.4$ $\mathrm{Hz}, J=8.8 \mathrm{~Hz}, 2 \mathrm{H}), 7.331-7.386(\mathrm{~m}, 3 \mathrm{H}), 7.462(\mathrm{t}, J=$ $8.4 \mathrm{~Hz}, J=7.6 \mathrm{~Hz}, 1 \mathrm{H}), 7.619(\mathrm{~d}, J=8.4 \mathrm{~Hz}, 2 \mathrm{H})$, $7.805(\mathrm{~d}, J=7.6 \mathrm{~Hz}, 2 \mathrm{H}), 7.859-7.895$ (m, 2H), 7.997 $(\mathrm{d}, \quad J=8.4 \mathrm{~Hz}, 1 \mathrm{H}) ; \quad$ ESI $\quad(+) \quad m / \mathrm{e}: 363.34$ $\left(\mathrm{M}^{+}+\mathrm{H}\right)(\% 100)$; anal. found: C 66.63, H 3.83, N 7.77, S
8.62; calcd. for $\mathrm{C}_{21} \mathrm{H}_{15} \mathrm{FN}_{2} \mathrm{OS} \cdot 0.5 \mathrm{HCl}$ : C 66.31, H 4.07, N 7.37, S 8.42.

2-[4-(4-chlorobenzamido)benzyl]benzothiazole (6i)

Yield: 64; m.p. $=203-205{ }^{\circ} \mathrm{C}$; IR $v / \mathrm{cm}^{-1}: 3351,1653$

(Amid I), 1598, 1530 (Amid II), 1509, 1485, 1427 (Amid III), 1093, 943-625, 726-625. ${ }^{1} \mathrm{H}$ NMR (400 $\left.\mathrm{MHz}, \mathrm{CDCl}_{3}\right) \delta / \mathrm{ppm}: 4.426(\mathrm{~s}, 2 \mathrm{H}), 7.330-7.379(\mathrm{~m}$, $3 \mathrm{H}), 7.434-7.525(\mathrm{~m}, 3 \mathrm{H}), 7.619(\mathrm{~d}, J=8 \mathrm{~Hz}, 2 \mathrm{H})$, $7.798(\mathrm{~d}, J=8.8 \mathrm{~Hz}, 2 \mathrm{H}), 7.881(\mathrm{~s}, 1 \mathrm{H}), 7.996(\mathrm{~d}, J=$ $8.4 \mathrm{~Hz}, 1 \mathrm{H}), 8.076(\mathrm{~d}, J=8.4 \mathrm{~Hz}, 1 \mathrm{H}) ; \mathrm{ESI}(+) \mathrm{m} / \mathrm{e}$ : $381.29\left(\mathrm{M}^{+}+\mathrm{H}+2\right)(\% 49), 379.28\left(\mathrm{M}^{+}+\mathrm{H}\right)(\% 100)$; anal. found: $\mathrm{C}$ 66.28, $\mathrm{H}$ 3.98, $\mathrm{N} 7.57, \mathrm{~S} 8.08$; calcd. for $\mathrm{C}_{21} \mathrm{H}_{15} \mathrm{ClN}_{2} \mathrm{OS}$ : C 66.57, H 3.99, N 7.39, S 8.46.

\section{2-[4-(4-bromobenzamido)benzyl]benzothiazole (6j)}

Yield: $45 ;$ m.p. $=180-182{ }^{\circ} \mathrm{C}$; IR $v / \mathrm{cm}^{-1}: 3347$, 1653(Amid I), 1597, 1529 (Amid II), 1508, 1482, 1427(Amid III), 1067, 942-623, 727-623. ${ }^{1} \mathrm{H}$ NMR (400 MHz, $\left.\mathrm{CDCl}_{3}\right) \delta / \mathrm{ppm}: 4.430$ (s, 2H), 7.328-7.386 $(\mathrm{m}, 3 \mathrm{H}), 7.462(\mathrm{t}, J=8 \mathrm{~Hz}, J=8.4 \mathrm{~Hz}, 1 \mathrm{H}), 7.607-$ $6.628(\mathrm{~m}, 4 \mathrm{H}), 7.727(\mathrm{~d}, J=8.4 \mathrm{~Hz}, 2 \mathrm{H}), 7.792-7.821$ $(\mathrm{m}, 2 \mathrm{H}), 7.995(\mathrm{~d}, J=8.4 \mathrm{~Hz}, 1 \mathrm{H})$; ESI $(+) m / \mathrm{e}: 425.20$ $\left(\mathrm{M}^{+}+2\right)(\% 95), 423.09\left(\mathrm{M}^{+}\right)(\% 97), 423.29\left(\mathrm{M}^{+}\right)(\% 100)$; anal. found: C 58.89, H 3.60, N 7.09, S 7.55; calcd. for $\mathrm{C}_{21} \mathrm{H}_{15} \mathrm{BrN}_{2} \mathrm{OS} \cdot 0.1 \mathrm{HCl}: \mathrm{C} 58.21, \mathrm{H} 3.54, \mathrm{~N} 6.57, \mathrm{~S}$ 7.51 .

2-[4-(4-nitrobenzamido)benzyl]benzothiazole (6k)

Yield $19 \%$; m.p. $=204-206{ }^{\circ} \mathrm{C}$. IR $v / \mathrm{cm}^{-1}: 3302,1656$ (Amid I), 1597, 1528 (Amid II), 1512, 1455, 1436 (Amid III), 1347, 932-622, 724-622. ${ }^{1} \mathrm{H}$ NMR (400 MHz, DMSO-d $\left.{ }_{6}\right) \delta /$ ppm: 4.469 (s, 2H), 7.384-7.431 (m, $3 \mathrm{H}), 7.498$ (t, $J=8 \mathrm{~Hz}, J=8.4 \mathrm{~Hz}, 1 \mathrm{H}), 7.790$ (d, $J=$ $8.8 \mathrm{~Hz}, 2 \mathrm{H}), 7.969(\mathrm{~d}, J=7.6 \mathrm{~Hz}, 1 \mathrm{H}), 8.025(\mathrm{~d}, J=8.4$ $\mathrm{Hz}, 1 \mathrm{H}), 8.197$ (d, $J=8.4,2 \mathrm{H}), 8.383(\mathrm{~d}, J=9.2 \mathrm{~Hz}$, $2 \mathrm{H}), \quad 10.633 \quad(\mathrm{~s}, \quad 1 \mathrm{H}) ; \quad$ ESI $\quad(+) \quad m / \mathrm{e}: 390.33$ $\left(\mathrm{M}^{+}+\mathrm{H}\right)(\% 100)$; anal. found: $\mathrm{C} 63.96, \mathrm{H} 3.95, \mathrm{~N} 10.67$, $\mathrm{S}$ 8.18; calcd. for $\mathrm{C}_{21} \mathrm{H}_{15} \mathrm{~N}_{3} \mathrm{O}_{3} \mathrm{~S} \cdot 0.2 \mathrm{H}_{2} \mathrm{O}: \mathrm{C} 64.18, \mathrm{H}$ 3.92, N 10.69, S 8.15.

\section{2-[4-(4-ethylbenzamido)benzyl]benzothiazole (6l)}

Yield: $54 \%$; m.p. $=177-179{ }^{\circ} \mathrm{C}$. IR $v / \mathrm{cm}^{-1}: 3306,3102$, 3059, 3035, 2961, 2924, 1651 (Amid I), 1608-1596, 1530 (Amid II), 1512, 1455, 1437 (Amid III), 970-616, 731-616. ${ }^{1} \mathrm{H}$ NMR (400 MHz, $\left.\mathrm{CDCl}_{3}\right) \delta / \mathrm{ppm}: 1.267(\mathrm{t}$, $J=7.6 \mathrm{~Hz}, J=7.6 \mathrm{~Hz}, 3 \mathrm{H}), 2.720$ (q, 2H), 4.431 (s, 2H), 7.302-7.384 (m, 5H), $7.460(\mathrm{t}, J=8.4 \mathrm{~Hz}, J=8.4$ $\mathrm{Hz}, 1 \mathrm{H}), 7.639$ (d, $J=8.4 \mathrm{~Hz}, 2 \mathrm{H}), 7.778-7.811$ (m, 4H), $7.998(\mathrm{~d}, J=8.4 \mathrm{~Hz}, 1 \mathrm{H})$; ESI $(+) m / \mathrm{e}: 373.35$ $\left(\mathrm{M}^{+}+\mathrm{H}\right)(\% 100)$; anal. found: C 74.20, H 5.30, N 7.79, S 8.69; calcd. for $\mathrm{C}_{23} \mathrm{H}_{20} \mathrm{~N}_{2} \mathrm{OS}$ : C 74.16, H 5.41, N 7.52, S 8.60 .

2-[4-(4-tert-butylbenzamido)benzyl]benzothiazole (6m) Yield: $38 \%$; m.p. $=156-158^{\circ} \mathrm{C}$. IR $v / \mathrm{cm}^{-1}: 3280,3061$, 2965, 2867, 1646 (Amid I), 1608-1597, 1532 (Amid II), 1515, 1455, 1438 (Amid III), 966-601, 725-601; ${ }^{1} \mathrm{H}$ 
NMR (400 MHz, $\mathrm{CDCl}_{3}$ ) $\delta / \mathrm{ppm}: 1.328$ (s, 9H), 4.399 (s, 2H), 7.314-7.349 (m, 3H), 7.424-7.463 (m, 3H), $7.635(\mathrm{~d}, J=8.8 \mathrm{~Hz} 2 \mathrm{H}), 7.775-7.797(\mathrm{~m}, 3 \mathrm{H}), 7.985$ $(\mathrm{d}, J=8 \mathrm{~Hz}, 1 \mathrm{H}), 8.030$ (s, $1 \mathrm{H})$; ESI $(+) m / \mathrm{e}: 401.38$ $\left(\mathrm{M}^{+}+\mathrm{H}\right)(\% 100)$; anal. found: C 75.06, H 5.71, N 7.26, S 8.08; calcd. for $\mathrm{C}_{25} \mathrm{H}_{24} \mathrm{~N}_{2} \mathrm{OS}$ : C 74.97, H 6.04, N 6.99, S 8.01 .

2-[4-(4-sec-butoxybenzamido)benzyl]benzothiazole (6n) Yield: 34 m.p. $=154-156{ }^{\circ} \mathrm{C}$. IR $v / \mathrm{cm}^{-1}: 3332,2972$, 1644 (Amid I), 1597-1575, 1536 (Amid II), 1506, 1455, 1436 (Amid III), 1254, 1029, 997-636, 729-636. ${ }^{1} \mathrm{H}$ NMR (400 MHz, $\left.\mathrm{CDCl}_{3}\right) \delta / \mathrm{ppm}: 0.980(\mathrm{t}, J=7.2 \mathrm{~Hz}, J$ $=7.6 \mathrm{~Hz}, 3 \mathrm{H}), 1.315(\mathrm{~d}, J=6.4 \mathrm{~Hz}, 3 \mathrm{H}), 1.609-1.799$ (m, 2H), 4.353-4.399 (m, 1H), $4.413(\mathrm{~s}, 1 \mathrm{H}), 6.921(\mathrm{~d}, J$ $=8.8 \mathrm{~Hz}, 2 \mathrm{H}), 7.320-7.355(\mathrm{~m}, 3 \mathrm{H}), 7.452(\mathrm{t}, J=8 \mathrm{~Hz}$, $J=8.4 \mathrm{~Hz}, 1 \mathrm{H}), 7.622(\mathrm{~d}, J=8.4 \mathrm{~Hz}, 2 \mathrm{H}), 7.785-7.823$ (m, 3H), $7.877(\mathrm{~s}, 1 \mathrm{H}), 7.992(\mathrm{~d}, J=8 \mathrm{~Hz}, 1 \mathrm{H})$; ESI $(+)$ m/e: $417.35\left(\mathrm{M}^{+}+\mathrm{H}\right)(\% 100)$; anal. found: $\mathrm{C} 72.36, \mathrm{H}$ 5.58, N 7.08, S 7.70; calcd. for $\mathrm{C}_{25} \mathrm{H}_{24} \mathrm{~N}_{2} \mathrm{O}_{2} \mathrm{~S}$ : C 72.09, H 5.81, N 6.72, S 7.70.

2-[4-(phenylacetamido)benzyl]benzothiazole (6o)

Yield: $60 \%$; m.p. $=196-198{ }^{\circ} \mathrm{C}$; IR $v / \mathrm{cm}^{-1}: 3277,3059$, 1656 (Amid I), 1597, 1535 (Amid II), 1507, 1452, 1433 (Amid III), 1235, 979-624, 729-624. ${ }^{1} \mathrm{H}$ NMR (400 $\left.\mathrm{MHz}, \mathrm{CDCl}_{3}\right) \delta / \mathrm{ppm}: 3.734$ (s, 2H), $4.372(\mathrm{~s}, 2 \mathrm{H}), 7.169$ (s, 1H), $7.273(\mathrm{~d}, J=8.4 \mathrm{~Hz}, 2 \mathrm{H}), 7.315-7.466(\mathrm{~m}, 9 \mathrm{H})$, 7.778 (d, $J=8 \mathrm{~Hz}, 1 \mathrm{H}), 7.973(\mathrm{~d}, J=8 \mathrm{~Hz}, 1 \mathrm{H})$; ESI (+) $m / \mathrm{e}: 359.34\left(\mathrm{M}^{+}+\mathrm{H}\right)(\% 100)$; anal. found: $\mathrm{C} 73.77, \mathrm{H}$ 5.09, N 8.15, S 9.09; calcd. for $\mathrm{C}_{22} \mathrm{H}_{18} \mathrm{~N}_{2} \mathrm{OS}$ : C 73.71, $\mathrm{H}$ 5.06, N 7.82, S 8.95.

\section{2-[4-(4-fluorophenylacetamido)benzyl]benzothiazole (6p)}

Yield: $30 \%$; m.p. $=180-182^{\circ} \mathrm{C}$. IR $v / \mathrm{cm}^{-1}: 3261,3052$, 1653 (Amid I), 1597, 1538 (Amid II), 1507, 1453, 1433 (Amid III), 1225, 950-619, 728-619; ${ }^{1} \mathrm{H}$ NMR (400 $\left.\mathrm{MHz}, \mathrm{CDCl}_{3}\right) \delta / \mathrm{ppm}: 3.677(\mathrm{~s}, 2 \mathrm{H}), 4.366(\mathrm{~s}, 2 \mathrm{H}), 7.059$ (t, $J=8.4 \mathrm{~Hz}, J=8.8 \mathrm{~Hz}, 2 \mathrm{H}), 7.254-7.346(\mathrm{~m}, 5 \mathrm{H})$, $7.404-7.460(\mathrm{~m}, 3 \mathrm{H}), 7.773(\mathrm{~d}, J=7.6 \mathrm{~Hz}, 1 \mathrm{H}), 7.964$ $(\mathrm{d}, J=8 \mathrm{~Hz}, 1 \mathrm{H})$; ESI $(+) \mathrm{m} / \mathrm{e}: 377.30\left(\mathrm{M}^{+}+\mathrm{H}\right)(\% 100)$; anal. found: $\mathrm{C} 69.71, \mathrm{H} 4.54, \mathrm{~N} 7.76, \mathrm{~S} 8.37$; calcd. for $\mathrm{C}_{22} \mathrm{H}_{17} \mathrm{FN}_{2} \mathrm{OS} \cdot 0.1 \mathrm{H}_{2} \mathrm{O}: \mathrm{C} 69.85, \mathrm{H} 4.58, \mathrm{~N} 7.40, \mathrm{~S}$ 8.47 .

\section{2-[4-(4-chlorophenylacetamido)benzyl]benzothiazole}

\section{(6q)}

Yield: $55 \%$; m.p. $=198-200{ }^{\circ} \mathrm{C}$; IR $v / \mathrm{cm}^{-1}: 3295,3052$, 2923, 1662 (Amid I), 1598, 1537 (Amid II), 1509, 1453, 1437 (Amid III), 1093, 967-639, 731-639. ${ }^{1} \mathrm{H}$ NMR $\left(400 \mathrm{MHz}, \mathrm{CDCl}_{3}\right) \delta / \mathrm{ppm}: 3.701$ (s, 2H), $4.386(\mathrm{~s}, 2 \mathrm{H})$, $7.099(\mathrm{~s}, 1 \mathrm{H}), 7.265-7.376(\mathrm{~m}, 7 \mathrm{H}), 7.417-7.473(\mathrm{~m}$, $3 \mathrm{H}), 7.787(\mathrm{~d}, J=8.4 \mathrm{~Hz}, 1 \mathrm{H}), 7.979(\mathrm{~d}, J=8 \mathrm{~Hz}, 1 \mathrm{H})$; ESI $\quad(+) \quad m / \mathrm{e}: \quad 393.30\left(\mathrm{M}^{+}+\mathrm{H}\right)(\% 100), \quad 395.34$ $\left(\mathrm{M}^{+}+\mathrm{H}+2\right)(\% 43)$; anal. found: $\mathrm{C}$ 67.13, $\mathrm{H}$ 4.07, $\mathrm{N} 7.66$, S 8.37; calcd. for $\mathrm{C}_{22} \mathrm{H}_{17} \mathrm{ClN}_{2} \mathrm{OS}$ : C $67.25, \mathrm{H} 4.36, \mathrm{~N}$ 7.13, S 8.16. 2-[4-(4-bromophenylacetamido)benzyl]benzothiazole (6r)

Yield: $58 \%$; m.p. $=206-208^{\circ} \mathrm{C}$; IR $v / \mathrm{cm}^{-1}: 3292,3039$, 1663 (Amid I), 1598, 1534 (Amid II), 1509, 1455, 1434 (Amid III), 1070, 973-627, 729-627; ${ }^{1} \mathrm{H}$ NMR (400 $\left.\mathrm{MHz}, \mathrm{CDCl}_{3}\right) \delta / \mathrm{ppm}: 3.658(\mathrm{~s}, 2 \mathrm{H}), 4.371(\mathrm{~s}, 2 \mathrm{H}), 7.192$ $(\mathrm{d}, J=8 \mathrm{~Hz}, 2 \mathrm{H}), 7.278(\mathrm{~d}, J=8.8 \mathrm{~Hz}, 2 \mathrm{H}), 7.329$ (t, $J$ $=7.2 \mathrm{~Hz}, J=8 \mathrm{~Hz}, 1 \mathrm{H}), 7.406-7.459(\mathrm{~m}, 3 \mathrm{H}), 7.496(\mathrm{~d}$, $J=8.4 \mathrm{~Hz}, 2 \mathrm{H}), 7.776(\mathrm{~d}, J=8.4 \mathrm{~Hz}, 1 \mathrm{H}), 7.966(\mathrm{~d}, J$ $=8 \mathrm{~Hz}, 1 \mathrm{H})$. ESI $(+) \mathrm{m} / \mathrm{e}: 437.21\left(\mathrm{M}^{+}\right)(\% 100), 439.22$ $\left(\mathrm{M}^{+}+2 \mathrm{H}\right)(\% 95)$; anal. found: $\mathrm{C} 60.13, \mathrm{H} 3.74, \mathrm{~N} 6.81, \mathrm{~S}$ 7.43; calcd. for $\mathrm{C}_{22} \mathrm{H}_{17} \mathrm{BrN}_{2} \mathrm{OS}$ : C 60.42, H 3.92, N $6.41, \mathrm{~S} 7.33$.

2-[4-(4-nitrophenylacetamido)benzyl]benzothiazole (6s) Yield: $64 \%$; m.p. $=205-207{ }^{\circ} \mathrm{C}$; IR $v / \mathrm{cm}^{-1}: 3254,1661$ (Amid I), 1598, 1538 (Amid II), 1513, 1455, 1436 (Amid III), 1347, 970-637, 738-637; ${ }^{1} \mathrm{H}$ NMR (400 MHz, DMSO-d $\left.{ }_{6}\right) \delta /$ ppm: 3.810 (s, 2H), 4.376 (s, 2H), $7.303(\mathrm{~d}, J=8.4 \mathrm{~Hz}, 2 \mathrm{H}), 7.348$ (t, $J=7.2 \mathrm{~Hz}, J=6.8$ $\mathrm{Hz}, 1 \mathrm{H}), 7.439$ (t, $J=6.8 \mathrm{~Hz}, J=7.2 \mathrm{~Hz}, 1 \mathrm{H}), 7.551-$ $7.593(\mathrm{~m}, 4 \mathrm{H}), 7.910(\mathrm{~d}, J=8.4 \mathrm{~Hz}, 1 \mathrm{H}), 7.959$ (d, $J=$ $8.4 \mathrm{~Hz}, 1 \mathrm{H}), 8.170(\mathrm{~d}, J=8.42 \mathrm{H}), 10.291$ (s, 1H); ESI (+) $m / \mathrm{e}: 404.32\left(\mathrm{M}^{+}+\mathrm{H}\right)(\% 100)$; anal. found: $\mathrm{C} 65.05, \mathrm{H}$ 4.39, N 10.50, S 7.88; calcd. for $\mathrm{C}_{22} \mathrm{H}_{17} \mathrm{~N}_{3} \mathrm{O}_{3} \mathrm{~S} \cdot 0.1$ $\mathrm{H}_{2} \mathrm{O}: \mathrm{C} 65.20, \mathrm{H} 4.28$, N 10.37, S 7.91.

\section{2-[4-(4-methylphenylacetamido)benzyl]benzothiazole (6t)}

Yield $48 \%$; m.p. $=181-183^{\circ} \mathrm{C}$; IR $v / \mathrm{cm}^{-1}: 3284,3116$, 3045, 2918, 1661 (Amid I), 1596, 1531 (Amid II), 1512, 1455, 1434 (Amid III), 975-620, 730-620. ${ }^{1} \mathrm{H}$ NMR (400 MHz, $\mathrm{CDCl}_{3}$ ) $\delta / \mathrm{ppm}: 2.340$ (s, 3H), 3.658 (s, 2H), 4.349 (s, 2H), 7.172-7.194 (m, 4H), $7.243(\mathrm{~d}, J=8.4$ $\mathrm{Hz}, 2 \mathrm{H}), 7.321$ (t, $J=7.2 \mathrm{~Hz}, J=8 \mathrm{~Hz}, 1 \mathrm{H}), 7.401-$ $7.462(\mathrm{~m}, 4 \mathrm{H}), 7.766(\mathrm{~d}, J=8 \mathrm{~Hz}, 1 \mathrm{H}), 7.964$ (d, $J=$ $8.4 \mathrm{~Hz}, 1 \mathrm{H})$; ESI $(+)$ m/e: $372.34\left(\mathrm{M}^{+}+\mathrm{H}\right)(\% 100)$; anal. found: $\mathrm{C} 74.16, \mathrm{H} 5.56, \mathrm{~N} 7.84, \mathrm{~S} 8.72$; calcd. for $\mathrm{C}_{23} \mathrm{H}_{20} \mathrm{~N}_{2} \mathrm{OS}$ : C 74.16, H 5.41, N 7.52, S 8.61.

\section{2-[4-(4-methoxyphenylacetamido)benzyl]benzothia-} zole $(6 \mathbf{u})$

Yield: $40 \%$; m.p. $=168-170{ }^{\circ} \mathrm{C}$. IR $v / \mathrm{cm}^{-1}: 3293,3118$, 3039, 2930, 1661 (Amid I), 1598, 1533 (Amid II), 1512, 1455, 1434 (Amid III), 1249, 1035, 975-620, 730-620. ${ }^{1} \mathrm{H}$ NMR (400 MHz, $\mathrm{CDCl}_{3}$ ) $\delta / \mathrm{ppm}: 3.657$ (s, 2H), 3.809 (s, 3H), $4.363(\mathrm{~s}, 2 \mathrm{H}), 6.908(\mathrm{~d}, J=8.4 \mathrm{~Hz}, 2 \mathrm{H})$, $7.223(\mathrm{~d}, J=8.8 \mathrm{~Hz}, 2 \mathrm{H}), 7.262(\mathrm{~d}, J=8.8 \mathrm{~Hz}, 2 \mathrm{H})$, 7.327 (t, $J=7.2 \mathrm{~Hz}, J=8.4 \mathrm{~Hz}, 1 \mathrm{H}), 7.401-7.462$ (m, 3H), 7.773 (d, $J=7.6 \mathrm{~Hz}, 1 \mathrm{H}), 7.969$ (d, $J=8.4 \mathrm{~Hz}$, $1 \mathrm{H})$; ESI $(+) m / \mathrm{e}: 389.33\left(\mathrm{M}^{+}+\mathrm{H}\right)(\% 100)$; anal. found: $\mathrm{C} 70.77, \mathrm{H}$ 5.23, $\mathrm{N}$ 7.45, $\mathrm{S}$ 8.33; calcd. for $\mathrm{C}_{23} \mathrm{H}_{20} \mathrm{~N}_{2} \mathrm{O}_{2} \mathrm{~S}$ : C 71.11, H 5.19, N 7.21, S 8.25.

2-[4-(3-phenylpropanamido)benzyl]benzothiazole (6v) Yield: $46 \%$; m.p. $=163-165^{\circ} \mathrm{C}$; IR $v / \mathrm{cm}^{-1}$ : 3295, 3188, 3120, 3059, 3028, 2898, 1661 (Amid I), 1600, 1535 (Amid II), 1511, 1452, 1422 (Amid III), 971- 
609, 730-621. ${ }^{1} \mathrm{H}$ NMR (400 MHz, DMSO-d ${ }_{6}$ ) $\delta / \mathrm{ppm}$ : 2.620 (t, $J=7.2 \mathrm{~Hz}, J=8 \mathrm{~Hz}, 2 \mathrm{H}), 2.909$ (t, $J=8 \mathrm{~Hz}$, $J=7.2 \mathrm{~Hz}, 2 \mathrm{H}) ; 4.401$ (s, 2H), 7.177-7.282 (m, 5H), $7.313(\mathrm{~d}, J=8.4 \mathrm{~Hz}, 2 \mathrm{H}), 7.387$ (t, $J=7.2 \mathrm{~Hz}, J=7.6$ $\mathrm{Hz}, 1 \mathrm{H}), 7.481$ (t, $J=7.2 \mathrm{~Hz}, J=8 \mathrm{~Hz}, 1 \mathrm{H}), 7.569$ (d, $J=8.4 \mathrm{~Hz}, 2 \mathrm{H}), 7.948(\mathrm{~d}, J=7.6 \mathrm{~Hz}, 1 \mathrm{H}) ; 8.004(\mathrm{~d}, J$ $=8 \mathrm{~Hz}, 1 \mathrm{H}) 9.952(\mathrm{~s}, 1 \mathrm{H})$; ESI $(+) \mathrm{m} / \mathrm{e}: 379.39$ $\left(\mathrm{M}^{+}+\mathrm{H}\right)(\% 100)$; anal. found: $\mathrm{C} 74.49, \mathrm{H} 5.07, \mathrm{~N} 7.89$, S 8.73; calcd. for $\mathrm{C}_{23} \mathrm{H}_{20} \mathrm{~N}_{2} \mathrm{OS}$ : C 74.16, H 5.41, N 7.52, S 8.61

\section{2-[4-(3-(4-metoxyphenyl)propanamido)benzyl]benzo-} thiazole (6w)

Yield: $64 \%$; m.p. $=153-155^{\circ} \mathrm{C}$; IR $v / \mathrm{cm}^{-1}: 3303,3188$, 3120, 3052, 2949, 2897, 1657 (Amid I), 1599, 1534 (Amid II), 1510, 1454, 1432 (Amid III), 1246, 1034, 951-612, 730-612. ${ }^{1} \mathrm{H}$ NMR (400 MHz, DMSO-d 6 ): $2.561(\mathrm{t}, J=7.2 \mathrm{~Hz}, J=8 \mathrm{~Hz}, 2 \mathrm{H}), 2.829(\mathrm{t}, J=8 \mathrm{~Hz}, J$ $=7.2 \mathrm{~Hz}, 2 \mathrm{H}), 3.689(\mathrm{~s}, 3 \mathrm{H}), 4.386(\mathrm{~s}, 2 \mathrm{H}), 6.826(\mathrm{~d}, J$ $=8.8 \mathrm{~Hz}, 2 \mathrm{H}), 7.143(\mathrm{~d}, J=8.4 \mathrm{~Hz}, 2 \mathrm{H}), 7.297(\mathrm{~d}, J=$ $8.4 \mathrm{~Hz}, 2 \mathrm{H}), 7.373$ (t, $J=7.2 \mathrm{~Hz}, J=7.6 \mathrm{~Hz}, 1 \mathrm{H})$, 7.468 (t, $J=7.2 \mathrm{~Hz}, J=7.2 \mathrm{~Hz}, 1 \mathrm{H}), 7.555(\mathrm{~d}, J=8.4$ $\mathrm{Hz}, 2 \mathrm{H}), 7.934$ (d, $J=7.6 \mathrm{~Hz}, 1 \mathrm{H}), 7.989$ (d, $J=7.6$ $\mathrm{Hz}, \quad 1 \mathrm{H}), 9.921$ (s, 1H). ESI $(+) \quad m / \mathrm{e}: 403.41$ $\left(\mathrm{M}^{+}+\mathrm{H}\right)(\% 100)$; anal. found: $\mathrm{C} 71.63, \mathrm{H} 5.14, \mathrm{~N} 7.30, \mathrm{~S}$ 8.08; calcd. for $\mathrm{C}_{24} \mathrm{H}_{22} \mathrm{~N}_{2} \mathrm{O}_{2} \mathrm{~S}$ : C 71.62, H 5.51, N 7.30, S 8.08.

\section{Microbiology}

Microorganisms

Klebsiella pneumoniae isolate, which has an extended spectrum beta lactamase enzyme (ESBL), Pseudomonas aeruginosa isolate (gentamicin-resistant), Escherichia coli isolate, which has an extended spectrum beta lactamase enzyme (ESBL), Bacillus subtilis isolate (resistant to ceftriaxon), Staphylococcus aureus isolate [meticilline-resistant (MRSA)], K. pneumoniae RSKK 574 (Refik Saydam National Public Health Agency Culture Collection), P. aeruginosa ATCC 25853 (American Type Culture Collection), E. coli ATCC 25922, B. subtilis ATCC 6633, S. aureus ATCC 25923, Candida albicans ATCC 10231.

\section{Methods}

Standard strains of $K$. pneumoniae RSKK 574, $P$. aeruginosa ATCC 25853, E. coli ATCC 25922, B. subtilis ATCC 6633, S. aureus ATCC 25923, $C$. albicans ATCC 10231 and clinical isolates of these microorganisms resistant to various antimicrobial agents were included in the study. Resistance was determined by Kirby Bauer Disk Diffusion method according to the guidelines of Clinical and Laboratory Standards Institute (CLSI) ${ }^{27}$ in the clinical isolates.

Standard powders of ampicillin trihydrate, gentamycin sulphate, rifampicin, ofloxacin, fluconazole and amphotericin B were obtained from the manufacturers. Stock solutions were dissolved in dimethylsulphoxide (ofloxacin), pH 8 phosphate buffer saline (PBS) (ampicilin trihydrate) methanol (rifampicin) and distilled water (gentamicin sulfate, fluconazole and amphotericin B). Newly $(\mathbf{6 a}-\mathbf{6 w})$ and previously (7a7k) synthesized compounds were dissolved in $80 \%$ DMSO-20 \% EtOH.

Bacterial isolates were subcultured in Mueller Hinton Agar (MHA) plates and incubated over night at $37{ }^{\circ} \mathrm{C}$ and $C$. albicans was subcultured in Sabouraud Dextrose Agar (SDA) plates at $35^{\circ} \mathrm{C}$ for $24-48 \mathrm{~h}$. The microorganisms were passaged at least twice to ensure purity and viability.

The solution of the newly (6a-6w) and previously (7a-7k) synthesized compounds and standard drugs were prepared at $400,200,100,50,25,12.5,6.25$, $3.125,1.562,0.78,0.39,0.19,0.095,0.047,0.024$ $\mu \mathrm{g} / \mathrm{ml}$ concentrations, in the wells of microplates by diluting in Mueller Hinton Broth (MHB).

Bacterial susceptibility testing was performed according to the guidelines of CLSI M100-S16. ${ }^{28}$ The bacterial suspensions used for inoculation were prepared at $10^{5} \mathrm{cfu} / \mathrm{ml}$ by diluting fresh cultures at MacFarland 0.5 density $\left(10^{7} \mathrm{cfu} / \mathrm{ml}\right)$. Suspensions of the bacteria at $10^{5} \mathrm{cfu} / \mathrm{ml}$ concentration were inoculated to the twofold diluted solution of the compounds. There were $10^{4} \mathrm{cfu} / \mathrm{ml}$ bacteria in the wells after inoculations. MHB was used for diluting the bacterial suspension and for twofold dilution of the compound. $80 \%$ DMSO-20 \% EtOH, methanol, DMSO, PBS, pure microorganisms and pure media were used as control wells. A $10 \mu \mathrm{l}$ bacteria inoculum was added to each well of the microdilution trays. The trays were incubated at $37{ }^{\circ} \mathrm{C}$ and $\mathrm{MIC}$ endpoints were read after $24 \mathrm{~h}$ of incubation.

C. albicans was subcultured in SDA plates, and incubated at $35^{\circ} \mathrm{C}$ for $24-48 \mathrm{~h}$ prior to antifungal susceptibility testing. Susceptibility testing was performed in RPMI-1640 medium with L-glutamine buffered $\mathrm{pH}$ 7 with 3-[N-morpholino]-propansulfonic acid (MOPS) and culture suspensions were prepared through the guideline of CLSI M27-A3. ${ }^{29}$ Yeast suspensions were prepared according to McFarland 0.5 density and a working suspension was made by a 1:100 dilution followed by a 1:20 dilution of the stock suspension $\left(2.5 \times 10^{3} \mathrm{CFU} / \mathrm{ml}\right)$. A $10 \mu \mathrm{l}$ yeast inoculum was added to each well of the microdilution trays. The trays were incubated at $35^{\circ} \mathrm{C}$ and MIC end points were read after $48 \mathrm{~h}$ of incubation.

All organisms were tested in triplicate in each run of the experiments. The lowest concentration of the compound that completely inhibits macroscopic growth was determined and minimum inhibitory concentrations (MICs) were reported in Table 1. 
Table 1. In vitro antimicrobial activities of 2-(4-(substitutedcarboxamido)benzyl/ phenyl)benzothiazoles

\begin{tabular}{|c|c|c|c|c|c|c|c|c|c|c|c|c|c|c|}
\hline & & & & & & $\begin{array}{l}\text { Gram-n } \\
\text { MIC }\end{array}$ & $\begin{array}{l}\text { gative } \\
\mathrm{lg} / \mathrm{ml})\end{array}$ & & & & $\begin{array}{r}\text { Gram- } \\
\text { MIC }\end{array}$ & $\begin{array}{l}\text { positive } \\
(\mu \mathrm{g} / \mathrm{ml})\end{array}$ & & $\begin{array}{c}\text { Yeast } \\
\operatorname{MIC}(\mu \mathrm{g} / \mathrm{ml})\end{array}$ \\
\hline $\begin{array}{l}\text { Comp. } \\
\text { no }\end{array}$ & $X$ & $\mathrm{Y}$ & $\mathrm{R}$ & K.p. & K.p. ${ }^{*}$ & P. $a$ & P.a.* & E.c. & E.c. ${ }^{*}$ & B.s. & B.s. * & S.a. & S.a. ${ }^{*}$ & C.a. \\
\hline $6 a$ & - & - & $\mathrm{H}$ & 25 & 50 & 25 & 25 & 25 & 50 & 25 & 50 & 50 & 25 & 25 \\
\hline $6 b$ & - & - & $\mathrm{OCH}\left(\mathrm{CH}_{3}\right) \mathrm{C}_{2} \mathrm{H}_{5}$ & 12.5 & 50 & 50 & 25 & 50 & 50 & 200 & 100 & 50 & 25 & 25 \\
\hline $6 c$ & - & $\mathrm{CH}_{2}$ & $\mathrm{H}$ & 25 & 50 & 50 & 25 & 50 & 25 & 200 & 50 & 50 & 25 & 25 \\
\hline $6 d$ & - & $\mathrm{CH}_{2}$ & $\mathrm{NO}_{2}$ & 25 & 25 & 12.5 & 25 & 12.5 & 50 & 25 & 50 & 50 & 12.5 & 25 \\
\hline $6 e$ & - & $\mathrm{C}_{2} \mathrm{H}_{4}$ & $\mathrm{H}$ & 25 & 25 & 25 & 6.25 & 25 & 12.5 & 25 & 50 & 50 & 12.5 & 25 \\
\hline $6 f$ & - & $\mathrm{C}_{2} \mathrm{H}_{4}$ & $\mathrm{OCH}_{3}$ & 25 & 12.5 & 50 & 12.5 & 25 & 25 & 200 & 50 & 25 & 12.5 & 25 \\
\hline $6 \mathrm{~g}$ & $\mathrm{CH}_{2}$ & - & $\mathrm{H}$ & 50 & 50 & 50 & 25 & 50 & 50 & 200 & 50 & 100 & 25 & 25 \\
\hline $6 \mathrm{~h}$ & $\mathrm{CH}_{2}$ & - & $\mathrm{F}$ & 50 & 50 & 50 & 25 & 50 & 50 & 50 & 100 & 50 & 25 & 25 \\
\hline $6 \mathbf{i}$ & $\mathrm{CH}_{2}$ & - & $\mathrm{Cl}$ & 50 & 50 & 50 & 50 & 50 & 50 & 50 & 50 & 25 & 25 & 25 \\
\hline $6 \mathbf{j}$ & $\mathrm{CH}_{2}$ & - & $\mathrm{Br}$ & 25 & 12.5 & 12.5 & 25 & 12.5 & 25 & 25 & 12.5 & 6.25 & 12.5 & 25 \\
\hline $6 k$ & $\mathrm{CH}_{2}$ & - & $\mathrm{NO}_{2}$ & 50 & 50 & 50 & 25 & 50 & 50 & 50 & 50 & 100 & 25 & 25 \\
\hline 61 & $\mathrm{CH}_{2}$ & - & $\mathrm{C}_{2} \mathrm{H}_{5}$ & 50 & 50 & 50 & 50 & 50 & 50 & 200 & 25 & 50 & 25 & 25 \\
\hline $6 m$ & $\mathrm{CH}_{2}$ & - & $\mathrm{C}\left(\mathrm{CH}_{3}\right)_{3}$ & 50 & 50 & 50 & 50 & 50 & 50 & 50 & 50 & 50 & 25 & 25 \\
\hline $6 n$ & $\mathrm{CH}_{2}$ & - & $\mathrm{OCH}\left(\mathrm{CH}_{3}\right) \mathrm{C}_{2} \mathrm{H}_{5}$ & 50 & 50 & 50 & 50 & 50 & 50 & 200 & 100 & 50 & 25 & 25 \\
\hline 60 & $\mathrm{CH}_{2}$ & $\mathrm{CH}_{2}$ & $\mathrm{H}$ & 50 & 50 & 25 & 25 & 50 & 50 & 50 & 50 & 50 & 25 & 25 \\
\hline $6 p$ & $\mathrm{CH}_{2}$ & $\mathrm{CH}_{2}$ & $\mathrm{~F}$ & 50 & 50 & 50 & 50 & 50 & 50 & 50 & 50 & 100 & 25 & 50 \\
\hline $6 q$ & $\mathrm{CH}_{2}$ & $\mathrm{CH}_{2}$ & $\mathrm{Cl}$ & 25 & 50 & 50 & 25 & 25 & 50 & 50 & 25 & 50 & 25 & 25 \\
\hline $6 r$ & $\mathrm{CH}_{2}$ & $\mathrm{CH}_{2}$ & $\mathrm{Br}$ & 50 & 50 & 50 & 50 & 50 & 50 & 25 & 50 & 50 & 25 & 25 \\
\hline $6 s$ & $\mathrm{CH}_{2}$ & $\mathrm{CH}_{2}$ & $\mathrm{NO}_{2}$ & 50 & 50 & 50 & 25 & 50 & 50 & 50 & 50 & 50 & 25 & 25 \\
\hline $6 t$ & $\mathrm{CH}_{2}$ & $\mathrm{CH}_{2}$ & $\mathrm{CH}_{3}$ & 25 & 25 & 12.5 & 25 & 50 & 12.5 & 25 & 25 & 25 & 12.5 & 25 \\
\hline $6 u$ & $\mathrm{CH}_{2}$ & $\mathrm{CH}_{2}$ & $\mathrm{OCH}_{3}$ & 50 & 50 & 25 & 25 & 50 & 50 & 50 & 50 & 50 & 25 & 25 \\
\hline $6 v$ & $\mathrm{CH}_{2}$ & $\mathrm{C}_{2} \mathrm{H}_{4}$ & $\mathrm{H}$ & 50 & 25 & 50 & 50 & 50 & 50 & 50 & 50 & 100 & 25 & 25 \\
\hline $6 w$ & $\mathrm{CH}_{2}$ & $\mathrm{C}_{2} \mathrm{H}_{4}$ & $\mathrm{OCH}_{3}$ & 25 & 50 & 50 & 25 & 25 & 50 & 50 & 50 & 50 & 25 & 25 \\
\hline $7 \mathbf{a}$ & - & - & $\mathrm{F}$ & 25 & 50 & 25 & 25 & 50 & 50 & 50 & 50 & 50 & 25 & 25 \\
\hline $7 b$ & - & - & $\mathrm{Cl}$ & 50 & 25 & 25 & 25 & 50 & 50 & 50 & 50 & 50 & 12.5 & 25 \\
\hline $7 c$ & - & - & $\mathrm{Br}$ & 50 & 50 & 25 & 25 & 50 & 50 & 50 & 100 & 50 & 25 & 25 \\
\hline $7 d$ & - & - & $\mathrm{C}_{2} \mathrm{H}_{5}$ & 25 & 50 & 25 & 25 & 25 & 50 & 50 & 50 & 50 & 6.25 & 12.5 \\
\hline $7 e$ & - & - & $\mathrm{C}\left(\mathrm{CH}_{3}\right)_{3}$ & 25 & 50 & 25 & 25 & 25 & 50 & 50 & 100 & 50 & 12.5 & 12.5 \\
\hline $7 f$ & - & - & $\mathrm{NO}_{2}$ & 50 & 50 & 25 & 25 & 25 & 50 & 50 & 50 & 50 & 12.5 & 12.5 \\
\hline $7 \mathrm{~g}$ & - & $\mathrm{CH}_{2}$ & $\mathrm{~F}$ & 50 & 50 & 25 & 25 & 25 & 50 & 50 & 25 & 100 & 50 & 25 \\
\hline $7 \mathrm{~h}$ & - & $\mathrm{CH}_{2}$ & $\mathrm{Cl}$ & 50 & 50 & 25 & 25 & 50 & 50 & 50 & 50 & 50 & 50 & 25 \\
\hline $7 \mathbf{i}$ & - & $\mathrm{CH}_{2}$ & $\mathrm{Br}$ & 50 & 50 & 12.5 & 25 & 25 & 50 & 50 & 50 & 50 & 25 & 12.5 \\
\hline $7 \mathbf{j}$ & - & $\mathrm{CH}_{2}$ & $\mathrm{CH}_{3}$ & 25 & 50 & 25 & 25 & 50 & 50 & 50 & 50 & 50 & 25 & 25 \\
\hline $7 \mathbf{k}$ & - & $\mathrm{CH}_{2}$ & $\mathrm{OCH}_{3}$ & 12.5 & 50 & 25 & 6.25 & 12.5 & 25 & 12.5 & 50 & 50 & 12.5 & 12.5 \\
\hline \multicolumn{4}{|c|}{ Ampicillin trihydrate } & - & - & - & - & 3.125 & 400 & 0.78 & 0.78 & 0.78 & - & - \\
\hline \multicolumn{4}{|c|}{ Gentamycin sulfate } & 0.39 & 6.25 & 1.562 & 50 & 0.78 & 12.5 & 0.39 & 0.19 & 0.78 & 6.25 & - \\
\hline \multicolumn{4}{|c|}{ Rifampicin } & - & - & - & - & - & - & 0.19 & 3.125 & 0.0225 & 1.562 & - \\
\hline \multicolumn{4}{|c|}{ Ofloxacin } & 0.19 & 3.125 & 6.25 & 50 & 0.19 & 6.25 & 0.19 & 3.125 & 0.19 & 1.562 & - \\
\hline \multicolumn{4}{|c|}{ Fluconazol } & - & - & - & - & - & - & - & - & - & - & 0.78 \\
\hline \multicolumn{4}{|c|}{ Amphotericin B } & - & - & - & - & - & - & - & - & - & - & 0.78 \\
\hline
\end{tabular}

Abbrevations: MIC: Minimum Inhibitory Concentration, K.p.: Klebsiella pneumoniae RSKK 574, K.p.*: K. pneumoniae isolate, P.a.: Pseudomonas aeruginosa ATCC 25853, P.a.*: P. aeruginosa isolate, E.c.: Escherichia coli ATCC 25922, E.c.*: E. coli isolate, B.s.: Bacillus subtilis ATCC 6633, B.s.*: B. subtilis isolate, S.a.: Staphylococcus aureus ATCC 25923, S.a.*: S. aureus isolate, C.a.: Candida albicans ATCC 10231. 


\section{RESULTS AND DISCUSSION}

\section{Chemistry}

The synthetic pathways for preparation of the target compounds listed in Table 1 are shown in Scheme 1 and Scheme 2 . The final compounds were easily obtained in two steps. In the first, 2-(4-aminobenzyl/phenyl)benzothiazole as a starting material was performed by condensing of appropriate aminophenols and suitable acids in polyphoshoric acid (Scheme 1). In the second reaction, an amidification was done. For this reaction, 2-(4aminobenzyl/phenyl)benzothiazole was treated with suitable carboxylic chloride obtained by using suitable carboxylic acid with thionyl chloride to get compounds 6a-6w as given in Scheme 2. The structures were supported by spectral data. The IR, ${ }^{1} \mathrm{H}$ NMR, Mass spectra and Elemental Analysis results are in agreement with the proposed structures. Physical and spectral data of the compounds are reported in Table 1. All of the compounds $(\mathbf{6 b}-\mathbf{6 w})$ are original except $\mathbf{6 a} .^{23}$

According to the spectroscopic data of the final compounds the IR showed characteristic $\mathrm{C}=\mathrm{O}$ (amide) stretching bands in the $1644-1670 \mathrm{~cm}^{-1}$ region. In the ${ }^{1} \mathrm{H}$ NMR spectra of the compounds $\mathbf{6 a}-\mathbf{6} \mathbf{w}$, the signal of NH proton was observed at $10.722-9.921 \mathrm{ppm}$ as a singlet band; $\mathrm{CH}_{2}$ protons between phenyl and benzothiazole ring were observed at $4.372-4.426 \mathrm{ppm}$ as a singlet band for compounds $\mathbf{6 g}-\mathbf{6} \mathbf{w} . \mathrm{CH}_{2}$ protons were observed at 3.810-3.658 ppm as a singlet band for compounds which carries phenylacetylamido moiety $(\mathbf{6 c}-$ 6d, 6o-6t). $-\mathrm{COCH}_{2} \mathrm{CH}_{2}$ protons were observed at $2.927-2.543 \mathrm{ppm}$ as triplet bands for compounds $\mathbf{6 e}, \mathbf{6} \mathbf{f}$, $\mathbf{6 v}, \mathbf{6 w}$. Besides, all the aromatic protons were observed at the expected regions. On the other hand, MASS spectra of the compounds showed $\mathrm{M}+\mathrm{H}$ peaks, since the electrospray ionization method was employed, in accordance with their formulas.

\section{Antimicrobial Activity}

All the newly $(\mathbf{6 a}-\mathbf{6 w})$ and previously $(\mathbf{7 a}-\mathbf{7 k})$ synthesized 2-[4-(4-substitutedbenzamido / phenylacetamido / phenylpropionamido) benzyl / phenyl]benzothiazole derivatives were in vitro tested for antibacterial activity against $K$. pneumoniae RSKK 574, $P$. aeruginosa ATCC 25853, E. coli ATCC 25922, K. pneumoniae isolate, which has an extended spectrum beta lactamase enzyme (ESBL), E. coli isolate (ESBL), P. aeruginosa isolate (gentamicin-resistant) as Gram-negative bacteria, B. subtilis ATCC 6633, S. aureus ATCC 25923, B. subtilis isolate (resistant to ceftriaxon), $S$. aureus isolate (meticilline-resistant (MRSA)) as Grampositive bacteria and the antifungal activity was evaluated against $C$. albicans ATCC 10231. The standard agents, ampicillin trihydrate, gentamycin sulfate, rifampicin and ofloxacin for antibacterial activity and fluconazole and amphotericin B for antifungal activity were also screened under identical conditions for quality control and comparison. The MIC values were determined by microdilution method according to the guidelines of Clinical and Laboratory Standards Institute (CLSI). ${ }^{28,29}$

The observed in vitro antimicrobial activity results of the tested compounds were given in Table 1 . The synthesized compounds were found showing an antibacterial activity at MIC values between 6.25-50 $\mu \mathrm{g} / \mathrm{ml}$ for Gram-negative bacteria. Among the tested compounds, 2-[4-(phenylpropionamido)phenyl]benzothiazole (6e) and 2-[4-(4-methoxyphenylacetamido)phenyl]benzothiazole (7k) were found the most potent derivative at a MIC value of $6.25 \mu \mathrm{g} / \mathrm{ml}$ against the screened drug-resistant enteric Gram-negative rod P.aeruginosa isolate providing three folds higher potency than the compared standard drugs; gentamycin sulfate and ofloxacin. On the other hand, 6f showed also good activity at a MIC value of 12.5 $\mu \mathrm{g} / \mathrm{ml}$ against the same microorganism. It revealed that the compound having phenyl acetamide moiety by holding a methoxy group on position $\mathrm{R}(\mathbf{6} \mathbf{f}, \mathbf{7 k})$ was performed one or two folds better activity against drug-resistant $P$. aeruginosa isolate than the other tested compounds. On the other hand, when $\mathrm{CH}_{2}$ group as a bridge between benzothiazole and phenyl came the activity against $P$. aeruginosa isolate pretty decreased as seen in Table 1 (compounds $6 \mathbf{6 e}$ and $\mathbf{6 f}$ compared to compounds $6 \mathbf{v}$ and $\mathbf{6 w}$ ). This means that planarity between phenyl on second position of benzothiazole and bicyclic structure is very important for potent antimicrobial activity against drug-resistant enteric Gram-negative rod P.aeruginosa. Among the tested compounds $\mathbf{6 f}$ and $\mathbf{6 j}$ are the most active with a MIC value of $12.5 \mu \mathrm{g} / \mathrm{ml}$ against drug-resistant $K$. pneumoniae. Only compounds $\mathbf{6 e}$ and $\mathbf{6 t}$ showed the same activity compared to standard drug Gentamycine sulfate against drug-resistant Gram-negative bacteria E.coli.

According to Table 1, the synthesized compounds showed a broad spectrum of activity with MIC values 200-6.25 $\mu \mathrm{g} / \mathrm{ml}$ against some Gram-positive bacteria such as $S$. aureus, B. subtilis and their drug resistant isolates. All the tested compounds indicated a moderate activity against $B$. subtilis. In addition, most of the compounds were found as showing one or two folds dilutions more antibacterial active against the screened drug resistant $S$. aureus isolate compared to the nonresistant S. aureus ATCC 25923 strain. The compound, 2-[4-(4ethylbenzamido)phenyl]benzothiazole (7d), indicated the most potent inhibitory effect against the drug resistant $S$. aureus isolate with $6.25 \mu \mathrm{g} / \mathrm{ml}$ MIC value 
showing as the same activity compared to gentamycin sulfate. The derivative, $\mathbf{6 j}$ showed more potent inhibitory effect with a MIC value of $6.25 \mu \mathrm{g} / \mathrm{ml}$ than the other compounds against $S$. aureus.

Moreover, most of the synthesized compounds exhibited a moderate antifungal activity for $C$. albicans with MIC values between $12.5-25 \mu \mathrm{g} / \mathrm{ml}$ except 6p. It can be concluded that the compound is holding a fluorine atom on position $\mathrm{R}$ of phenyl ring at phenylacetamido moiety instead of benzamido play a decisive role for the antifungal activity against C.albicans.

\section{CONCLUSION}

Because of the need of new antibacterial drugs active against the multi-drug resistance bacteria, herein, we synthesized 2-[4-(4-substitutedbenzamido / phenylacetamido / phenylpropionamido) benzyl / phenyl]benzothiazole derivatives $(\mathbf{6 a - 6 w})$ as a new antimicrobial agents in order to be able to contribute to the antimicrobial researchers.

In according to our present study, it can be proposed, that 2-phenylbenzothiazole moiety was found to be more important than 2-benzylbenzothiazole for enhancing potency against Gram-negative bacteria especially the drug-resistant $P$. aeruginosa isolate. Furthermore, benzamide moiety at position 2 of benzothiazole ring was more important for increasing potency against the Gram-positive $S$. aureus.

These observations provide some predictions in order to design further antimicrobial active compounds prior to their synthesis following with QSAR and molecular modelling studies.

Acknowledgements. This work was supported by TUBITAK 107S455 (SBAG-COST BM0701-19). The Central Laboratory of the Faculty of Pharmacy of Ankara University provided support for acquisition of the NMR, mass spectrometer and elemental analyzer used in this work.

\section{REFERENCES}

1. F. C. Tenover, J. W. Biddle, and M. V. Lancaster, Emerg. Infect. Dis. 7 (2001) 327.

2. D. Livermore, Int. J. Antimicrob. Agents 16 (2000) (Suppl. 1) S3.

3. K. Poole, Curr. Opin. Microbiol. 4 (2001) 500.

4. K. Coleman, Drug Discov. Today Ther. Strateg. 1 (2004) 455.

5. D. Abbanat, M. Macielag, and K. Bush, Expert Opin. Investig. Drugs 12 (2003) 379.

6. G. Trapani, A. Latrofa, M. Franco, D. Armenise, F. Morlacchi, and G. Liso, Arzneim. Forsch. 44 (1994) 969.
7. I. Yalcin, I. Oren, E. Sener, A. Akin, and N. Ucartürk, Eur. J. Med. Chem. 27 (1992) 401.

8. I. Yildiz-Oren, I. Yalcin, E. Aki-Sener, and N. Uçartürk, J. Med. Chem. 39 (2004) 291.

9. H. Kucukbay and B. Durmaz, Arzneim.-Forsch./Drug Res. 47 (1997) 667.

10. P. H. Kalina, D. J. Shetlar, R. A. Lewis, L. J. Kullerstrand, and R. F. Brubaker, Ophthalmology 95 (1988) 772.

11. R. Paramashivappa, P. Phani Kumar, P. V. Subba Rao, and A. Srinivasa Rao, Bioorg. Med. Chem. Lett. 13 (2003) 657.

12. J. Koci, V. Klimesova, K. Waisser, J. Kaustova, H. M. Dahse, and U. Mollmann, Bioorg. Med. Chem. Lett. 12 (2002) 3275.

13. L. Katz, Contribution from the Schenley Laborator, 75 (1953) 712.

14. J. Surin J. Trop. Med. Public Health 26 (1995) 128.

15. Y. Komatsu and N. Minami, Chem. Pharm. Bull. 43 (1995) 1614.

16. T. Kagaya, A. Kajiwara, S. Nagato, K. Akasaka, and A. Kubota, J. Pharmacol. Exp. Ther. 278 (1996) 243.

17. I. R. Ager, A. C. Barnes, G. W. Danswan, P. W. Hairsine, D. P. Kay, P. D. Kennewell, S. S. Matharu, P. Miller, P. Robson, D. A. Rowlands, W. R. Tully, and R. Westwood, J. Med. Chem. 31 (1988) 1098.

18. A. Pinar, P. Yurdakul, I. Yildiz-Oren, O. Temiz-Arpaci, N. L. Acan, E. Aki-Sener, and I. Yalcin, Biochem. Biophys Res Comm. 317 (2004) 670.

19. O. Temiz-Arpaci, B. Tekiner-Gulbas, I. Yildiz, E. Ak1-Sener, and I. Yalcin, Bioorg. Med. Chem. 13 (2005) 6354.

20. B. Tekiner-Gulbas, O. Temiz-Arpaci, I. Yildiz, E. Akı-Sener, and I. Yalcin, SAR and QSAR Env. Res. 17 (2006) 121.

21. D. F. Shi, T. D. Bradshaw, S. Wrigley, C. J. McCall, P. Lelieveld, I. Fichtner, and M. F. G. Stevens, J. Med. Chem. 39 (1996) 3375.

22. I. Hutchinson, S. A. Jennings, B. R. Vishnuvajjala, A. D. Westwell, and M. F. G. Stevens, J. Med. Chem. 45 (2002) 744.

23. M. Chua, D. Shi, S. Wrigley, T. D. Bradshaw, I. Hutchinson, P. N. Shaw, D. A. Barrett, L. A. Stanley, and M. F. G. Stevens $J$. Med. Chem. 42 (1999) 381.

24. K. Bolelli, I. Yalcin, T. Ertan-Bolelli, S. Ozgen, F. KaynakOnurdag, I. Yildiz, and E. Aki, Med. Chem. Res. 21 (2011) 3818.

25. M. F. G. Stevens, C. J. McCall, and P. Lelieveld, Benzazole compounds for use in therapy, EP 0721336 B1 (1999).

26. I. Yalcin, B. Kocyigit-Kaymakcioglu, I. Oren, E. Sener, O. Temiz, A. Akin, and A. Altanlar, (1997). Il Farmaco 52 p.685.

27. Clinical and Laboratory Standards Institute (CLSI) (2006a), (formerly NCCLS), Performance Standards for Antimicrobial Disk Susceptibility Tests, Approved Standard, M2-A9, Clinical and Laboratory Standards Institute, 940 West Valley Road, Wayne, Pennsylvania, USA.

28. Clinical and Laboratory Standards Institute (CLSI) (2006b). (formerly NCCLS), Performance Standards for Antimicrobial Susceptibility Testing, 16th Informational Supplement. CLSI M100-S16, Clinical and Laboratory Standards Institute, 940 West Valley Road, Wayne, Pennsylvania, USA.

29. Clinical and Laboratory Standards Institute (CLSI) (2006c). (formerly NCCLS), Reference Method for Broth Dilution Antifungal Susceptibility Testing Yeast, Approved standard, M27A3, Clinical and Laboratory Standards Institute, 940 West Valley Road, Wayne, Pennsylvania, USA. 